\title{
A new approach to screening cancer stem cells from the U251 human glioma cell line based on cell growth state
}

\author{
XIANGMEI CAO ${ }^{1,2^{*}}, \mathrm{YU} \mathrm{GU}^{1 *}$, LINA JIANG $^{1}$, YINGMEI WANG ${ }^{1}$, FANG LIU $^{1}$, YUQIAO XU ${ }^{1}$, \\ JUNXIA DENG ${ }^{3}$, YAYUN NAN ${ }^{4}$, LIYING ZHANG $^{1}$, JING YE $^{1}$ and QING LI ${ }^{1}$ \\ ${ }^{1}$ State Key Laboratory of Cancer Biology and Department of Pathology, Xijing Hospital, \\ Fourth Military Medical University, Xi'an; ${ }^{2}$ Department of Pathology, Basic Medical School, \\ Ningxia Medical University, Yinchuan; Departments of ${ }^{3}$ Pediatrics and ${ }^{4}$ Traditional Chinese Medicine, \\ Xijing Hospital, Fourth Military Medical University, Xi'an, P.R. China
}

Received October 10, 2012; Accepted December 3, 2012

DOI: 10.3892/or.2012.2206

\begin{abstract}
Cancer stem cells (CSCs) play important roles in the biological behaviour of malignant tumours. To study their properties, they must be carefully identified and purified. Cancer cells can acquire three different morphological types during single cell cloning. A small subpopulation of clones acquires a regular and compact shape, and these clones are enriched for CSCs; however, the majority of clones have an irregular morphology with loose intercellular junctions, with fewer characteristics of CSCs. At present, the main method to isolate CSCs is to collect the regular clones in low-density culture conditions; therefore, an insufficient amount of CSCs is obtained for clonal expansion. To obtain a more sufficient amount of CSCs, the clones with an irregular and loose morphology were examined in our study. We found a small subpopulation of U251 glioma cells that arrested in the suspended state and that subsequently migrated to form new clones. The suspended cells were isolated from the irregular and loose clones. Clonogenic assays were performed in which $43.70 \%$ of the suspended cells and $32.91 \%$ of the adherent cells formed new clones. To determine the biological differences between the suspended and adherent cells, carboxyfluorescein succinimidyl ester (CFSE) labelling, MTT assays, and cell cycle assays were performed. The results demonstrated that the suspended cells had the characteristics of CSCs, including higher proliferation rates, as well as selfmaintenance and self-renewal capabilities, and they stained positively for markers of brain CSCs and had multilineage
\end{abstract}

Correspondence to: Dr Qing Li or Dr Jing Ye, State Key Laboratory of Cancer Biology and Department of Pathology, Xijing Hospital, Fourth Military Medical University, 169 Changle West Road, Xi'an 710032, P.R. China

E-mail: liqing@fmmu.edu.cn

E-mail: yejing@fmmu.edu.cn

*Contributed equally

Key words: cancer stem cells, glioma, cell clone, suspended cells potential. Thus, we established a new and efficient approach for screening CSCs from the U251 human glioma cell line based on the cell growth state.

\section{Introduction}

Malignant tumours consist of a heterogeneous population of cells that differ in their expression of markers and growth capacities $(1,2)$. The cancer stem cell (CSC) hypothesis provides new insight into the heterogeneity of malignant tumours. Heterogeneity is determined, at least in part, by the presence of CSCs (1-6). Therefore, it is important to improve screening methods to obtain sufficient amounts of CSCs for further study of the biological treatment of malignant tumours.

Stem cells and committed cells can form distinct clones in vitro (7). CSCs can be obtained by monoclonal morphology screening in some cancer cell lines. In the glioma cell line, $\mathrm{U} 251$, clones are characterised as tight, intermediate, or loose. The clones with a round and compact shape (tight clones) consist of CSCs, while the irregular (intermediate clones) and looseshaped clones did not show any CSC properties (8). Therefore, the intermediate- and loose-shaped clones have not been extensively studied. Similar clone patterns have been observed in malignant cell lines, such as head and neck squamous cell carcinoma, breast carcinoma and prostate carcinoma cell lines, in which only the cells of tight clones were capable of selfrenewal (9-11). These studies also indicated that the majority of the clones were intermediate $(61.0 \%)$ and loose $(27.1 \%)$, and only a few were tight (11.9\%) (8).

In the present study, both suspended and adherent cells were present in each clonal subpopulation grown under the same culture conditions. Cells were collected from the intermediate and loose clones, which were hypothesised to contain CSCs, and cultured in neurobasal medium supplemented with growth factors. The suspended cells from these populations displayed significant 'stemness', while the adherent cells did not. In this experiment, a new and efficient screening method for isolating CSCs based on their growth state was implemented to enrich for CSCs from the glioma cell line, U251. This method provided a shorter detection time and simplified the procedures; future studies using these cells are required. 


\section{Materials and methods}

Cell culture. Human glioma cells (U251) were cultured in DMEM/F12 (Gibco, Grand Island, NY, USA) supplemented with $10 \%$ fetal bovine serum (FBS; Hangzhou Sijiqing Biological Engineering Materials Co., Ltd., China). The U251 cells were thoroughly dissociated with $0.125 \%$ trypsin to prepare single-cell suspensions and then cultured in 100-mm dishes at a density of $30-50$ cells $/ \mathrm{cm}^{2}(8)$. After incubation for two weeks at $37^{\circ} \mathrm{C}$ with $5 \% \mathrm{CO}_{2}$ and $100 \%$ humidity, clones of different morphological types were observed. Subsequently, the single-cell suspensions were cultured in 24-well plates at a clonal density (8). The intermediate and loose clones were selected and the cells were gently blown using a glass dropper to obtain the suspended cells. The same numbers of suspended and adherent cells were used in the subsequent experiments.

Self-renewal assay and induction of differentiation. The suspended cells $\left(1 \times 10^{4}\right.$ cells $\left./ \mathrm{ml}\right)$ were cultured in neurobasal medium, which consisted of serum-free DMEM/F12 supplemented with $20 \mathrm{ng} / \mathrm{ml}$ basic fibroblast growth factor (bFGF; Peprotech, Rocky Hill, NJ, USA), $20 \mathrm{ng} / \mathrm{ml}$ epidermal growth factor (EGF; Peprotech), and $20 \mu \mathrm{l} / \mathrm{ml}$ B27 (Invitrogen, Carlsbad, CA, USA), and primary clone spheres were formed. Subsequently, primary clone spheres were dissociated with stem cell accutase (Gibco) to prepare single-cell suspensions from which secondary clone spheres were formed. For immunofluorescence staining, individual suspended cells and clone spheres were cultured in serum-free DMEM/F12 for no more than $2 \mathrm{~h}$ to allow attachment to the slide. To induce differentiation, the clone spheres were cultured in DMEM/F12 with $10 \%$ FBS. Immunofluorescence staining was performed after $72 \mathrm{~h}$.

Carboxyfluorescein succinimidyl ester (CFSE) labelling. CFSE has been widely used in the study of cell proliferation, including measurement of the percentage of proliferation (12). A CFSE stock (20 mM in DMSO; Dojindo, Kumamoto, Japan) stored at $-20^{\circ} \mathrm{C}$ was thawed and diluted in PBS without $\mathrm{Ca}^{2+}$ and $\mathrm{Mg}^{2+}$ to the desired working concentration $(10 \mu \mathrm{M})$. The labelled cells were cultured in DMEM/F12 with $10 \%$ FBS for four and seven days. The CFSE contents of the cultured cells were estimated with a FACSCalibur flow cytometer and CellQuest software (BD Biosciences, San Diego, CA, USA).

MTT assay. The suspended and adherent cells were each seeded into 96 -well plates $\left(9-10 \times 10^{4}\right.$ cells $\left./ \mathrm{ml}\right)$ in DMEM/F12 with $10 \%$ FBS. The growth curves were determined by an MTT ( $5 \mathrm{mg} / \mathrm{ml}$; Sigma, St. Louis, MO, USA) assay that measures absorbance at a wavelength of $570 \mathrm{~nm}$.

Cell cycle and clonogenic assay. The cells $\left(5-10 \times 10^{5}\right.$ cells $)$ were trypsinised and washed twice with $2.5 \mathrm{ml}$ ice-cold PBS and then re-suspended in $1 \mathrm{ml}$ PBS and fixed with $2 \mathrm{ml}$ ethanol. The cell cycle stage was analysed with a FACSCalibur flow cytometer and CellQuest software (BD Biosciences). For analysis of secondary clone formation, the suspended and adherent cells were plated in $100-\mathrm{mm}$ dishes at a density of $150-200$ cells/ $/ \mathrm{cm}^{2}$ (8) and cultured in DMEM/F12 with $10 \%$ FBS. Subsequently, the clones containing 100-200 cells were counted.
Immunofluorescence microscopy and dyes. The single suspended cells and clone spheres (before and after differentiation) were fixed in $4 \%$ paraformaldehyde for $30 \mathrm{~min}$, permeabilised with $1 \%$ Triton X-100 in PBS for 15 min, and blocked with 3\% BSA for 20 min before adding the following primary antibodies: mouse anti-human Nestin (1:100; Santa Cruz Biotechnology Inc., Santa Cruz, CA, USA), rabbit antihuman CD133 (1:100; Abcam, Cambridge, MA, USA), rabbit anti-human glial fibrillary acidic protein (GFAP; 1:100; Zhongshan Bio-Tech Co., Zhongshan, Guangdong, China), rabbit anti-human $\beta_{\mathrm{III}}$-tubulin (1:2000; Sigma-Aldrich), and mouse anti-human MBP (1:100; Santa Cruz Biotechnology Inc.). Hoechst 33258 (Invitrogen) was used to stain the cell nuclei. Images were obtained with an Olympus fluorescence microscope. The contrast and brightness of the micrographs were then adjusted using Adobe Photoshop CS for data presentation.

Statistical analyses. The one-way ANOVA test or the Student's $\mathrm{t}$-test was used to determine statistical significance using SPSS 16.0 software. P-values $<0.05$ were considered to indicate statistically significant differences. All quantitative data are presented as the means \pm standard deviation.

\section{Results}

Suspended cells are present in the tight, intermediate and loose clones. U251 cells formed three morphological types of clones in low-density culture conditions: tight, intermediate and loose clones. The tight clones with a regular and compact shape contained tightly packed cells. The intermediate clones were not as regular as the tight clones, with the inner cells being tightly packed, while the peripheral cells were loosely aligned and had multiple shapes. The loose clones contained spindleshaped or flat cells that were loosely aligned. Some suspended cells were contained in the clones (Fig. 1A). The tight, intermediate and loose clones comprised 13.97, 45.25 and 40.78\% of the total clonal population, respectively. The suspended cells comprised $14.06 \pm 7.61,15.16 \pm 6.52$ and $12.84 \pm 4.48 \%$ of the tight, intermediate, and loose clonal populations, respectively, and no significant difference was found among them according to statistical analysis (Fig. 1B). Both the suspended and adherent cells were collected from the intermediate and loose clones and cultured in neurobasal medium for $48 \mathrm{~h}$. The suspended and adherent cells maintained their former growth patterns (Fig. 1C).

Suspended cells have a higher proliferation capacity. CSFE is distributed to both daughter cells by mitosis; therefore, CSFE fluorescence decreases with cell proliferation (13). The suspended and adherent cells were labelled by CSFE at the same time and then were plated in culture dishes. After culturing for four and seven days, the CSFE fluorescence of the suspended cells was significantly less than that of the adherent cells (four-day suspended cells, $7.3 \pm 0.4 \%$; adherent cells, $8.7 \pm 0.2 \%$; seven-day suspended cells, $0.9 \pm 0.1 \%$; adherent cells, $2.1 \pm 0.1 \%$ ) (Fig. 2A and B). Furthermore, the growth curve, measured using the MTT assay, showed a significantly higher absorbance in the suspended cell cultures from days three to seven compared to the adherent cells (Fig. 2C). These 


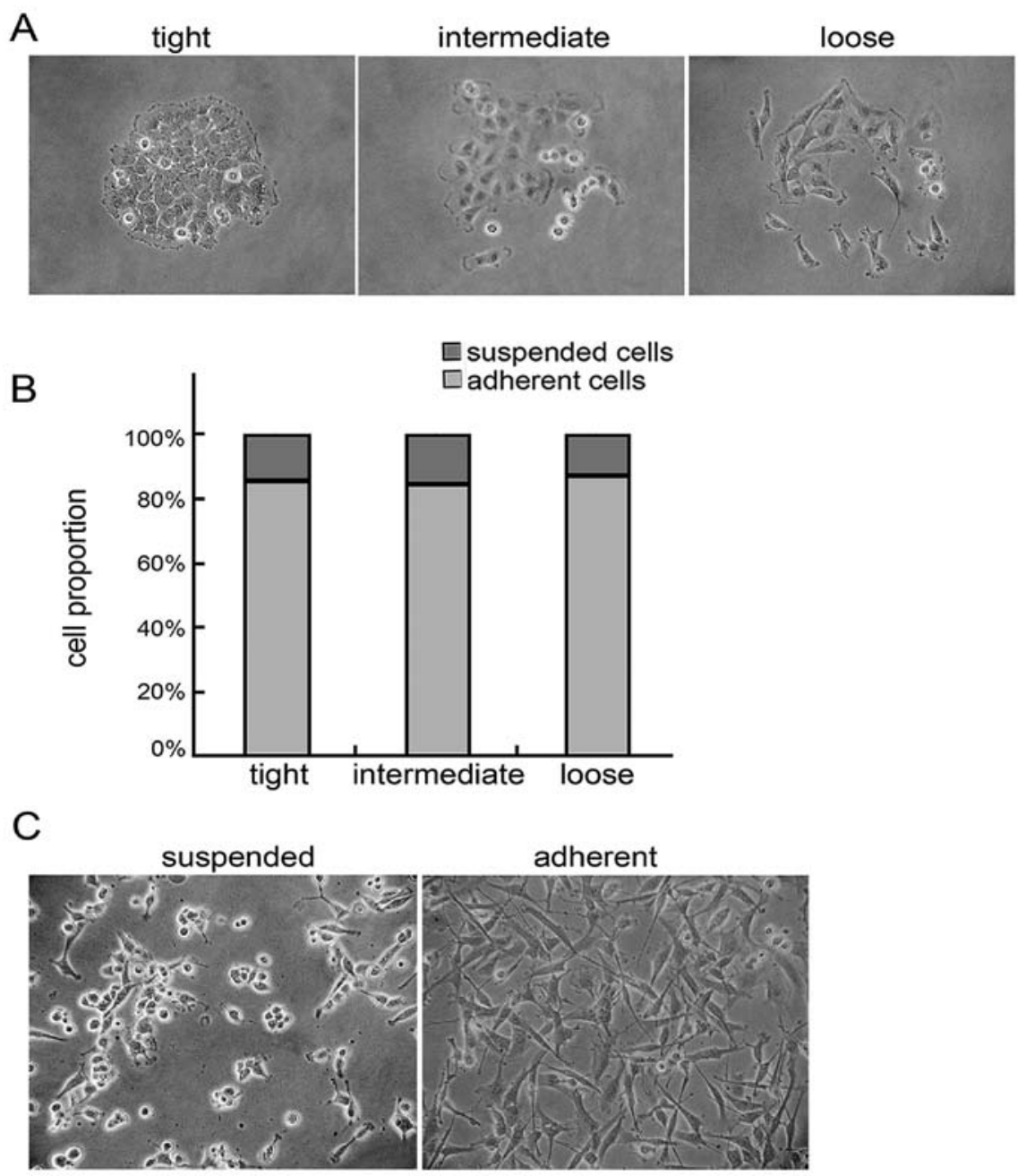

Figure 1. Suspended cells were present in the tight, intermediate and loose clones. (A) U251 cells had three types of morphological variations: tight, intermediate and loose clones. Some suspended cells were contained in the clones (magnification, x100). (B) The proportions of suspended cells and adherent cells were calculated, and no difference was found between them by one-way ANOVA $(\mathrm{P}>0.05)$. (C) Adherent and suspended cells were cultured in neurobasal medium for $48 \mathrm{~h}$; the suspended cells, but not the adherent cells, remained in suspension.

results indicate that suspended cells have a higher proliferation capacity than adherent cells.

Suspended cells have the potential for self-maintenance. To maintain a similar cell growth pattern, the suspended cells were cultured in neurobasal medium and the adherent cells were cultured in DMEM/F12 with $10 \%$ FBS for $48 \mathrm{~h}$. The suspended cells had a significantly higher number of cells in the G0 and G1 phases (suspended cells, 40.5 $\pm 2.2 \%$; adherent cells, $34.69 \pm 1.67 \%$ ) and a significantly lower number in the $S$ phase (suspended cells, 9.86 $\pm 0.37 \%$; adherent cells, 22.78 $\pm 1.05 \%$ ) (Fig. 3A). A clonogenic assay was then carried out, and it was found that $43.70 \%$ of the suspended cells formed secondary clones, which was a significantly higher percentage than those formed by the adherent cells (32.91\%) (Fig. 3B).

Suspended cells have the potential for self-renewal, multilineage differentiation, and the expression of markers of brain CSCs. We performed tests to identify the 'stem-like' characteristics of the suspended cells. In neurobasal culture medium, a single suspended cell formed a primary clone sphere within four days. These primary clone spheres gradually increased in size. On day seven, the primary clone spheres were dissociated into the single cells and cultured in the same neurobasal culture medium. The secondary clone spheres had smoother edges after seven days. The clone spheres were differentiated in DMEM/F12 with $10 \%$ FBS. They tightly attached to the dishes, and the cells grew out and around the spheres (Fig. 4A). Glial fibrillary acidic protein (GFAP), $\beta_{\mathrm{III}}$-tubulin and myelin basic protein (MBP), differentiation markers for astrocytes, neurons and oligodendrocytes, respectively, were found to be positively expressed in the differentiated cells by indirect immunofluoresence (Fig. 4B). These results suggest that the suspended cells had the capacity for self-renewal and multilineage differentiation. Furthermore, CD133 and nestin, markers of brain CSCs, were detected by indirect immunofluoresence. As shown in Fig. 4C, CD133 and nestin were positively expressed in both the single suspended cells and clone spheres. CD133 was negatively expressed in the adherent cells. Nestin was weakly expressed in parts of the adherent cells, while most of the adherent cells had a negative nestin expression. Based on these results, the suspended cells derived from intermediate and loose clones may be CSCs. 
A
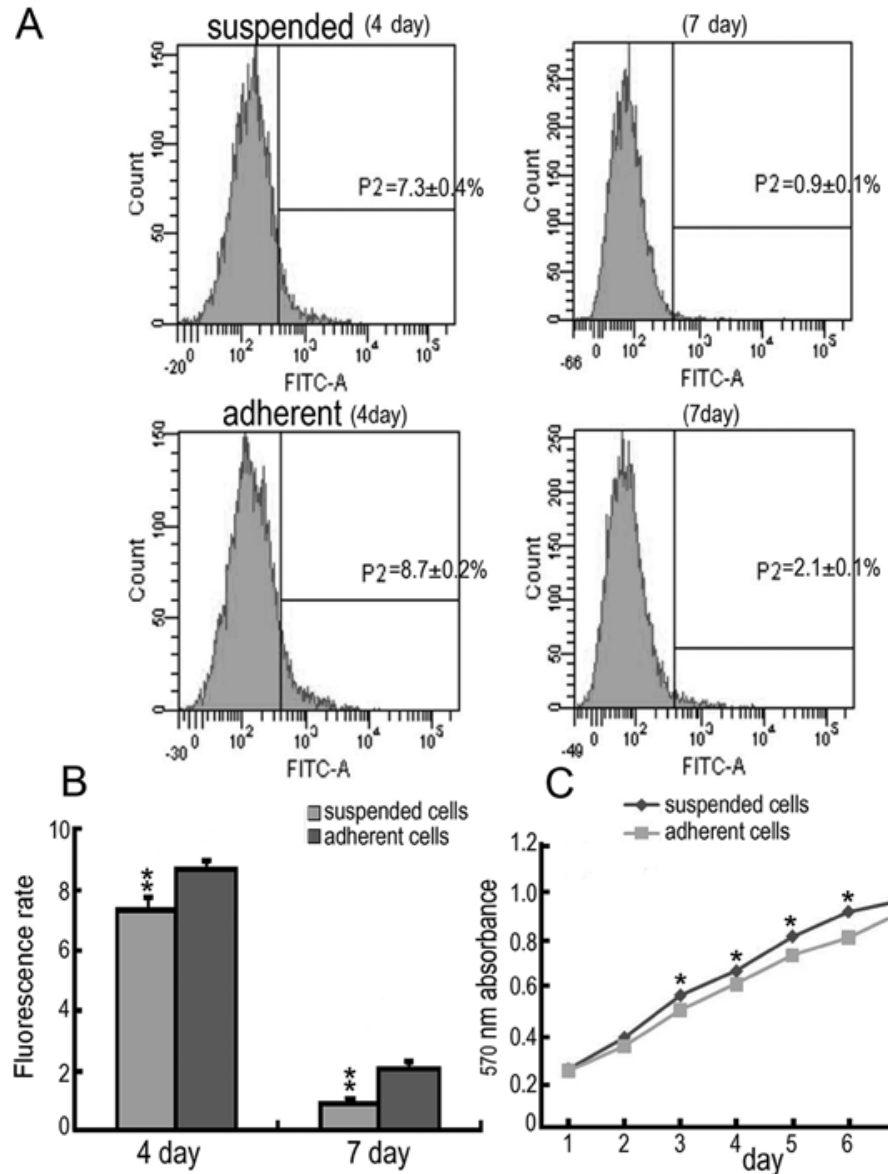

C

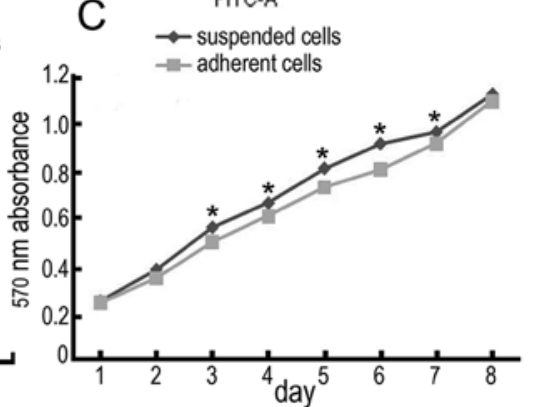

Figure 2. The suspended cells had a higher proliferation capacity. (A and B) Cell proliferation was determined by flow cytometry of CSFE labelling. 'P2' denotes the CSFE fluorescence rate, which was decreased with cell proliferation. The rate of suspended cells was significantly lower than that of adherent cells on the fourth and seventh day $\left({ }^{* *} \mathrm{P}<0.01\right)$. (C) From the third to the seventh day, the absorbance of the suspended cells was significantly higher than that of the adherent cells in the MTT assay ( $\left.{ }^{*} \mathrm{P}<0.05\right)$. The set of graphs are representative of three replicates. Statistical significance was determined by the Student's t-test.

A
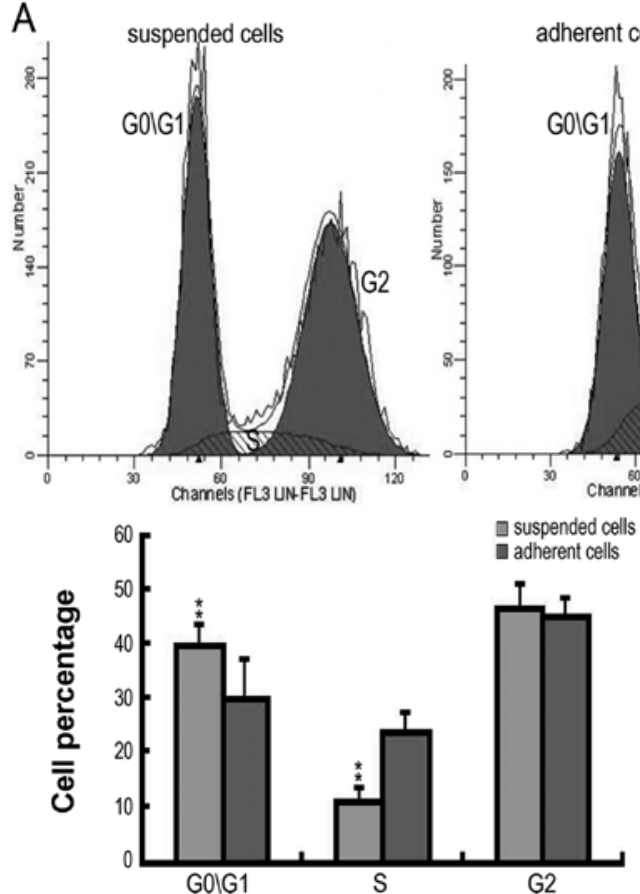

B
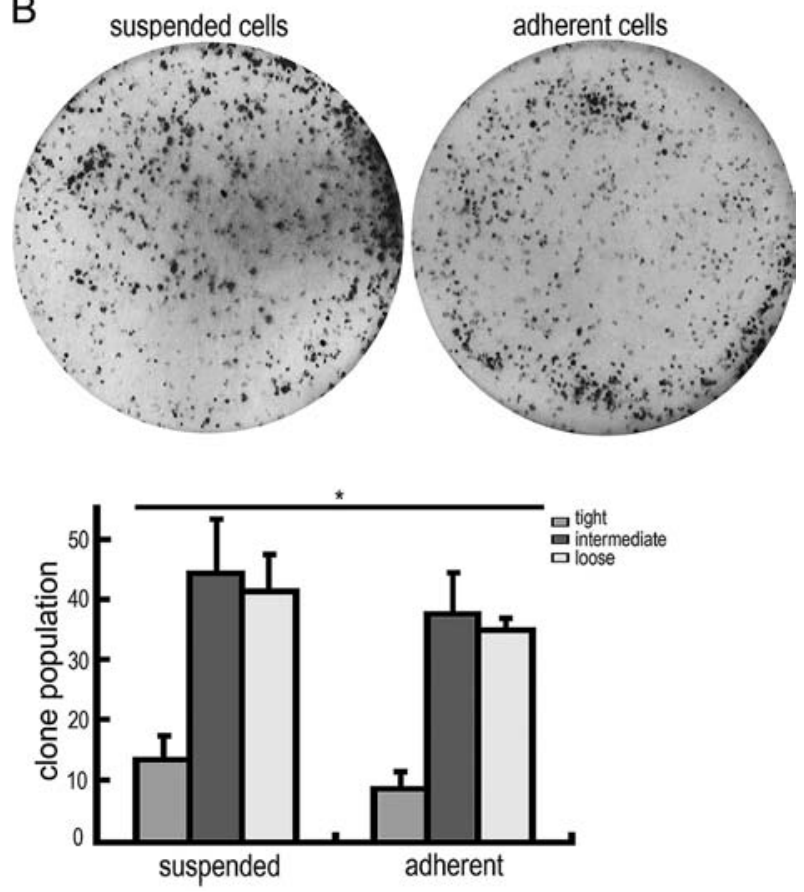

Figure 3. The suspended cells had the potential for self-maintenance. (A) There was a significantly higher number of suspended cells in the G0 and G1 phase of the cell cycle and a significantly lower number in the $\mathrm{S}$ phase compared to the adherent cells ( $\left.{ }^{* *} \mathrm{P}<0.01\right)$. (B) The population of secondary clones of suspended cells was significantly higher than that of the adherent cells ( $\mathrm{P}<0.05)$. The set of graphs is representative of three replicates. Statistical significance was determined by the Student's t-test. 


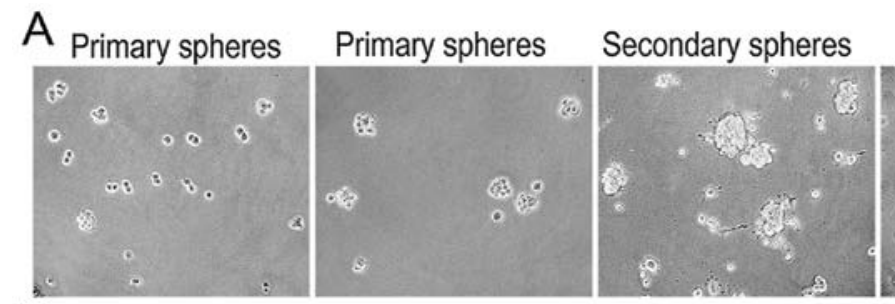

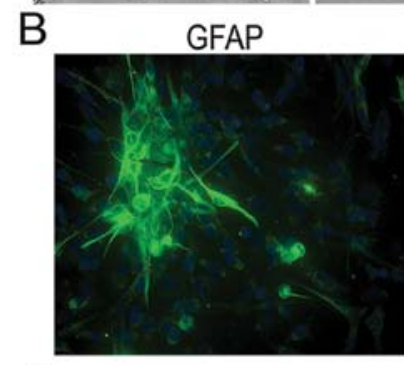
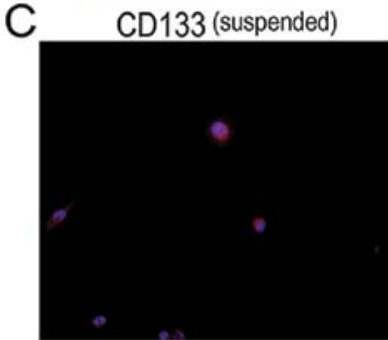

nestin (suspended)

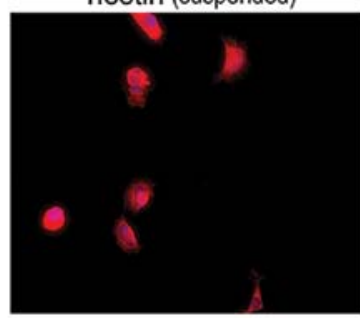

$\beta_{\text {II-tubulin }}$

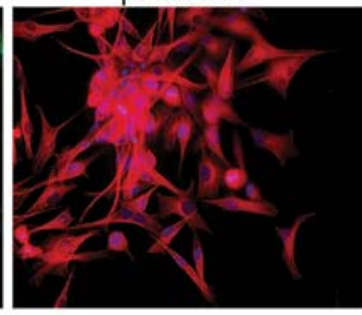

(sphere)

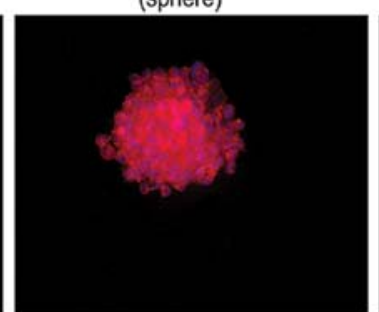

(sphere)

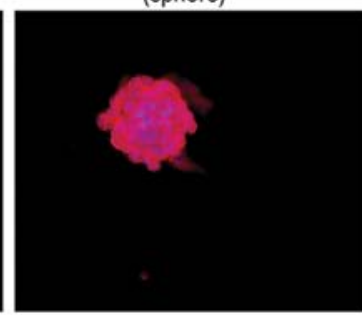

Differentiation

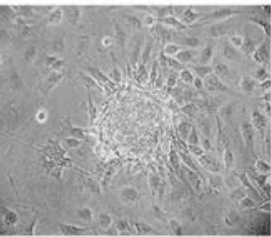

MBP

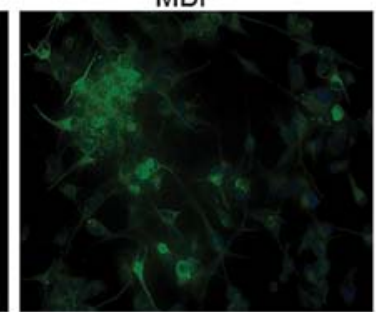

(adherent)

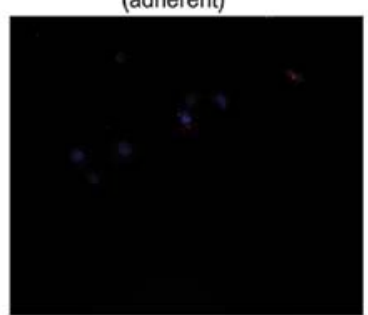

(adherent)

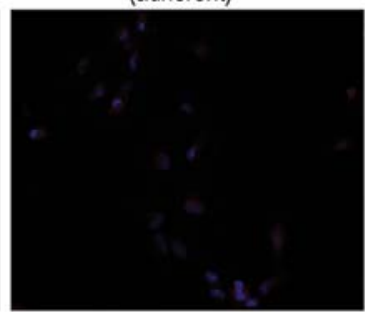

Figure 4. The suspended cells had the potential for self-renewal, multilineage differentiation and the expression of markers of brain CSCs. (A) Images of small primary clone spheres containing no more than five cells or larger primary clone spheres with approximately ten cells. In comparison, the secondary clone spheres had smoother edges. Differentiated cells grew around the spheres (magnification, $\mathrm{x} 100)$. (B) GFAP, $\beta_{\mathrm{III}}$-tubulin and MBP were found to be positively expressed in the differentiated cells. (C) CD133 and nestin were positively expressed in both singly suspended cells and the clone spheres. CD133 was negatively expressed in adherent cells. Nestin was weakly expressed in parts of the adherent cells, while most of the cells had a negative nestin expression. All fluorescent stains were observed under a fluorescence microscope (magnification, x400). The nuclei were stained with Hoechst 33258.

\section{Discussion}

CSCs determine the biological behaviour of malignant tumours. Stem cells are rare in the majority of tissues, and they must be carefully identified and purified based on their properties (14). In vitro culture systems may solve this problem. CSCs can be obtained from primary culture and cancer cell line screening, of which, the primary culture of fresh cancer samples is the most common method. However, it is difficult to obtain a large amount of samples that can be maintained for a long period of time, as the samples are often derived from patients undergoing surgical resection. Therefore, cell line screening may overcome this difficulty.

Cells can form distinct morphological types of clones in vitro (7). For example, when cloning individual epidermal keratinocytes, the clones acquire three different morphological types (7). In epithelial cancer cell lines, clone morphology has been used to determine whether clones originate from CSCs or committed cells (9-11). It has also been concluded that CSCs can be obtained from tight clones from the U251 glioma cell line (8). In this study, to obtain a larger amount of CSCs, the irregular and loose morphological clones were examined. A certain proportion of the suspended cells from the intermediate and loose clones were found to migrate elsewhere and develop new clones comparable to the tight morphology. The suspended cells had the ability to remain suspended in the neurobasal medium, while the adherent cells did not. Based on previous experiments, this may be due to the growth state of the CSCs. Thus, we hypothesised that CSCs exist in intermediate and loose clones and may potentially be utilised to obtain a larger amount of CSCs.

Previous studies have shown that stem cells have the ability to: i) proliferate, ii) exhibit self-maintenance, iii) self-renew to generate new cells, iv) generate a large number of progeny, and v) retain their multilineage potential over time (15). In this study, we showed that the suspended cells displayed significantly higher capacities for proliferation and clonogenicity and higher proportions of cells in the G0 and G1 phases than adherent cells. 
The suspended cells positively expressed MBP, $\beta_{\mathrm{III}}$ tubulin and GFAP, markers for mature oligodendrocytes, neurons, and astrocytes, respectively, after clonal differentiation (16). Our results demonstrate that these cells have a multilineage potential and may exhibit the properties of stem cells $(17,18)$. Some CSCs have been identified and screened based on different cell surface markers, culture conditions, or functional criteria (19). In neurobasal medium supplemented with growth factors, such as epidermal growth factor or basic fibroblast growth factor, CSCs can be propagated and expanded indefinitely, grown into spheres, and stained for CD133 and nestin, markers of brain CSCs, whereas the majority of differentiating or differentiated cells rapidly die (20-22). We verified that the suspended cells formed clone spheres, while the adherent cells did not.

Clearly, the intermediate and loose clones contained a proportion of CSCs. The results did not contradict previous studies. Suspended cells may be easily lost during experiments or perhaps they are not considered as cells of interest by others. A large number of suspended cells was carefully collected in our experiments, so that we could observe their distinct characteristics. Although the proportion of suspended cells decreased and the intermediate and loose cells became more prevalent with subsequent clonal expansion, we were able to obtain a larger amount of CSCs. The monoclonal morphology screening method has been used in a previous study (8). For each experiment, it was necessary to culture single cells in low-density cultures to achieve monoclonal morphology. Then, tight clones were selected and cultured in neurobasal medium to form clone spheres, which have a longer testing potential. However, a simpler and more effective method was used in this study. The suspended cells were gently dislodged with a glass dropper and cultured in neurobasal medium, which resulted in the rapid formation of clone spheres. This method provided a shorter detection time and simplified the procedures; accidents such as cell pollution were also avoided. First, the adherent committed cells were not repeatedly passaged to purify the suspended CSCs. Second, monoclonal morphology screening which was time-consuming was not required.

In the current study, only one glioma cell line (U251) was studied. However, we found that three morphological types of clones also developed from the C6 rat glioma cell line in lowdensity culture conditions, and a certain quantity of suspended cells was present in each clone. A similar result from other glioma cell lines may be obtained, which may be useful for CSC culture in the future.

\section{Acknowledgements}

We thank the members of our Laboratory of the Fourth Military Medical University for technical assistance. This study was supported by grants (81000171 and 8170798 ) from the National Natural Science Foundation of China and the State Key Laboratory of Cancer Biology (CBSKL 201103).

\section{References}

1. Dalerba P, Cho RW and Clarke MF: Cancer stem cells: models and concepts. Annu Rev Med 58: 267-284, 2007.
2. Vermeulen L, Sprick MR, Kemper K, Stassi G and Medema JP: Cancer stem cells - old concepts, new insights. Cell Death Differ 15: 947-958, 2008.

3. Heppner GH: Tumor heterogeneity. Cancer Res 44: 2259-2265, 1984.

4. Lapidot T, Sirard C, Vormoor J, Murdoch B, Hoang T, CaceresCortes J, Minden M, Paterson B, Caligiuri MA and Dick JE: A cell initiating human acute myeloid leukaemia after transplantation into SCID mice. Nature 367: 645-648, 1994.

5. Al-Hajj M, Wicha MS, Benito-Hernandez A, Morrison SJ and Clarke MF: Prospective identification of tumorigenic breast cancer cells. Proc Natl Acad Sci USA 100: 3983-3988, 2003.

6. Singh SK, Clarke ID, Terasaki M, Bonn VE, Hawkins C, Squire J and Dirks PB: Identification of a cancer stem cell in human brain tumors. Cancer Res 63: 5821-5828, 2003.

7. Barrandon $\mathrm{Y}$ and Green H: Three clonal types of keratinocyte with different capacities for multiplication. Proc Natl Acad Sci USA 84: 2302-2306, 1987.

8. Zhou ZH, Ping YF, Yu SC, Yi L, Yao XH, Chen JH, Cui YH and Bian XW: A novel approach to the identification and enrichment of cancer stem cells from a cultured human glioma cell line. Cancer Lett 281: 92-99, 2009.

9. Harper LJ, Piper K, Common J, Fortune F and Mackenzie IC: Stem cell patterns in cell lines derived from head and neck squamous cell carcinoma. J Oral Pathol Med 36: 594-603, 2007.

10. Locke M, Heywood M, Fawell S and Mackenzie IC: Retention of intrinsic stem cell hierarchies in carcinoma-derived cell lines. Cancer Res 65: 8944-8950, 2005.

11. Li H, Chen X, Calhoun-Davis T, Claypool K and Tang DG: PC3 human prostate carcinoma cell holoclones contain self-renewing tumor-initiating cells. Cancer Res 68: 1820-1825, 2008.

12. Banks HT, Sutton KL, Thompson WC, et al: A new model for the estimation of cell proliferation dynamics using CFSE data. J Immunol Methods 373: 143-160, 2011.

13. Evrard B, Dosgilbert A, Jacquemot N, Demeocq F, Gilles T, Chassagne J, Berger $M$ and Tridon A: CFSE flow cytometric quantification of lymphocytic proliferation in extracorporeal photopheresis: use for quality control. Transfus Apher Sci 42: $11-19,2010$.

14. Reya T, Morrison SJ, Clarke MF and Weissman IL: Stem cells, cancer, and cancer stem cells. Nature 414: 105-111, 2001.

15. Reynolds BA and Weiss S: Clonal and population analyses demonstrate that an EGF-responsive mammalian embryonic CNS precursor is a stem cell. Dev Biol 175: 1-13, 1996.

16. Campos B, Wan F, Farhadi M, Ernst A, Zeppernick F, Tagscherer KE, Ahmadi R, Lohr J, Dictus C, Gdynia G, Combs SE, Goidts V, Helmke BM, Eckstein V, Roth W, Beckhove P, Lichter P, Unterberg A, Radlwimmer B and HeroldMende C: Differentiation therapy exerts antitumor effects on stem-like glioma cells. Clin Cancer Res 16: 2715-2728, 2010.

17. Hemmati HD, Nakano I, Lazareff JA, Masterman-Smith M, Geschwind DH, Bronner-Fraser M and Kornblum HI: Cancerous stem cells can arise from pediatric brain tumors. Proc Natl Acad Sci USA 100: 15178-15183, 2003.

18. Vermeulen L, Todaro M, de Sousa Mello F, Sprick MR, Kemper K, Perez Alea M, Richel DJ, Stassi G and Medema JP: Single-cell cloning of colon cancer stem cells reveals a multilineage differentiation capacity. Proc Natl Acad Sci USA 105: $13427-13432,2008$.

19. Tabatabai G and Weller M: Glioblastoma stem cells. Cell Tissue Res 343: 459-465, 2011.

20. Singh SK, Hawkins C, Clarke ID, Squire JA, Bayani J, Hide T, Henkelman RM, Cusimano MD and Dirks PB: Identification of human brain tumour initiating cells. Nature 432: 396-401, 2004.

21. Günther HS, Schmidt NO, Phillips HS, Kemming D, Kharbanda S, Soriano R, Modrusan Z, Meissner H, Westphal M and Lamszus K: Glioblastoma-derived stem cell-enriched cultures form distinct subgroups according to molecular and phenotypic criteria. Oncogene 27: 2897-2909, 2008.

22. Shi CJ, Gao J, Wang M, Wang X, Tian R, Zhu F, Shen M and Qin RY: CD133(+) gallbladder carcinoma cells exhibit selfrenewal ability and tumorigenicity. World J Gastroenterol 17: 2965-2971, 2011. 